entitled "Devitrification", affords an illustration of the progress which is being made in solving these abstruse problems with the aid of the phase rule ; similar problems which concern the mixture of silicates present in igneous rocks are being studied in like manner and with remarkable success at the Geophysical Laboratory in Washington.

To many, the chapter on optical properties will be found of special interest; optical glass has been recognized as one of the key materials of civilization and an essential munition. Lens designers, who demand varying relations between refractive index and dispersion, have caused a wide search for suitable glass compositions, which has in turn led to the production of highly specialized glasses-- for example, those which are transparent to X-rays and ultra-violet light, or conversely which are opaque to these wave-lengths: both are now articles of commerce. There can also be obtained coloured glasses which are opaque to all but a narrow spectral range. It is most convenient to have the data in regard to the action of glass on light collected in one chapter, and the extent of the information may be judged from the fact that no fewer than thirty-six optical glasses manufactured by Chance Brothers are listed with their optical properties and approximate composition.

The examples selected indicate the remarkable thoroughness of the book, which is well worth even the high price charged for it.

\title{
Experimental Psychology
}

\section{Experimental Psychology}

By Robert S. Woodworth. Pp. xi +889 . (London : Methuen and Co., Ltd., 1938.) 18s. net.

TWENTY years ago it was still possible to get 1 the main results of the application of experiment to the problems of psychology within a reasonably small volume, and several excellent text-books were produced for that time. The rapid increase in the amount of published experimental work has made all such books out of date, and the teacher of experimental psychology has been forced to use seriously incomplete text-books and to supplement them in his teaching by his own knowledge of the technical journals. The task of making a single volume representive of the present position of experimental psychology seemed too laborious for accomplishment. This, however, has now been done by Prof. R. S. Woodworth, and his book will be welcomed by all students of the subject.

Prof. Woodworth has good qualifications for this task. It is particularly fortunate that he is free from a common tendency amongst psychologists to work under the banner of some particular school and to evaluate all work from the point of view of that school. The author's freedom from such fads enables him to deal fairly with experimental investigations of many different types and to recognize valuable work whether it is done by behaviourists or by Gestalt psychologists. At the same time, this catholicity of choice does not involve an absence of critical judgment. Few things can be duller than psychological volumes which are mere records of published researches, good, bad and indifferent. Prof. Woodworth seems to have used as his criterion for the inclusion of any piece of experimental work the fact that it makes a genuine contribution to the understanding of some psychological problem, and the general correctness of his judgment on this matter makes his book both useful and interesting.

If we treat the book as a survey of the present position of experimental psychology, we can find in it causes for satisfaction and a good many for dissatisfaction. This book should be a complete answer to those who complain that in the years since experimental psychology developed, nothing has been found out in psychological laboratories. There is, nevertheless, still much conflict about simple matters of fact, which is a result of the inconclusiveness of many published researches. Many experiments are carried out on too few subjects and with insufficient regard for the necessities of experimental design and of the statistical treatment of results. Very commonly the raw data from which the experimenter draws his conclusions are not published, so that no one else can ever determine how well justified his conclusions are. It is, for example, surprising to find in this book how many of the results of quantitative experiments are given as percentages without any indication of the actual numbers from which they have been derived. The methods of design and report of many experiments seem indeed to have been devised for the purpose of making it certain that no intelligible conclusion shall ever be drawn from them.

This, however, is a matter that is improving and it is to be hoped that severer standards in devising experiments and reporting their results will much lighten the task of a psychologist who, ten years hence, may try to make a new survey of the complete field of experimental achievement in psychology.
R. H. THOULess. 